\title{
Influence of Cardiorespiratory Fitness and Parental Lifestyle on Adolescents' Abdominal Obesity
}

\author{
Susana Vale ${ }^{1}$ Luísa Soares-Miranda ${ }^{1}$ Rute Santos ${ }^{1,2}$ Carla Moreira ${ }^{1}$ Ana Isabel \\ Marques ${ }^{1}$ Paula Santos ${ }^{1,3}$ Laetitia Teixeira $^{4}$ Jorge Mota $^{1}$ \\ ${ }^{1}$ Research Centre in Physical Activity Health and Leisure. Faculty of Sport Sciences - University \\ of Porto \\ ${ }^{2}$ Maia Higher School Education - Porto \\ ${ }^{3}$ School of Health Technology of Porto - Institute Polytechnic of Porto \\ ${ }^{4}$ Research and Training Centre in Adult and Elderly - Institute of Biomedical Sciences Abel \\ Salazar. University of Porto
}

\begin{abstract}
Aim: The aims of this study were (1) to analyze the influence of cardiorespiratory fitness (CRF) and parent's overweight status (POS) and socioeconomic status (SES) on abdominal obesity. Subjects and methods: This study comprised of 779 adolescents (12 to18 years). Waist-height ratio (WHtR), 20m shuttle-run test to ascertain CRF, POS according to World Health Organisation recommendations and SES of parents using level of education were analysed.

Results: Using WHtR, the prevalence of abdominal obesity was $21.3 \%(23.5 \%$ girls and $17.9 \%$ boys; $p=0,062$ ). Regardless of gender, participants who belonged to the $\mathrm{WHtR}$ risk group had significantly $(p \leq 0.05)$ lower CRF scores than the WHtR non-risk group. $84.4 \%$ of girls who belonged to the $\mathrm{WH}$ tR risk group had one or two overweight parents $(p \leq 0.05)$. Boys with low CRF (OR: 6.43; Cl: 3.33 - 12.39) were more likely to belong to the WHtR risk group compared with their lean peers. Girls with low CRF (OR: 1.78; $\mathrm{Cl}: 1.14-2.78$ ) and with at least one overweight parent (OR: 2.50; Cl: $1.07-5.85$ ) or two overweight parents (OR: 4.90; Cl: 2.0811.54) were associated with the risk of abdominal obesity.

Conclusion: This study highlights the influence of adolescents' family on abdominal obesity, especially in girls. Further, our data suggested that low CRF was a strong predictor of risk values of abdominal obesity in adolescence.
\end{abstract}

During recent decades prevalence of childhood obesity has been rising in many parts of the world (WHO 2000). A recent national report showed a high prevalence of overweight and obesity in Portuguese youngsters (Sardinha et al. 2010). While childhood obesity is associated with increased risk of chronic disease in adulthood (Ortega et al. 2008), there is also evidence showing that obese children may experience more illness and health related problems in childhood (Wijga et al. 2010). In this context, as the onset of obesity lies in early childhood, it is of great importance to examine the risk trends in order that effective preventive strategies targeting those at risk can start as early as possible.

The origin of obesity is complex and is influenced by genetic and environmental factors. For instance, it has been shown that the offspring of obese parents have a risk of obesity due to shared genes and shared environment (Harrap et al. 2000). However, most studies focusing on the relationship of parental obesity (BMI) with the obesity status of their offspring have provided some contradictory findings (Davey Smith et al. 2007, Kivimaki et al. 2007, Li et al. 2009). Within obesity status, abdominal obesity, a status of excessive accumulation of both central subcutaneous and visceral fat, has emerged as a main predictor for metabolic complications and adverse health effects in both adults (Sardinha L. B. et al. 2000) and youth (Rizzo et al. 2007, Teixeira et al. 2001). Additionally, obesity has been linked to low physical fitness, especially low cardiorespiratory fitness (CRF). Indeed, a large number of studies have shown a significant and inverse relationship between CRF and body fatness (Deforche et al. 2003, Kim et al. 2005, Mota et al. 2006). Lower CRF has been especially negatively and consistently associated with total and central body fat in adolescents (Moliner-Urdiales et al. 2009). Indeed, those who are physically fit maintain a more favourable caloric balance and lower body weight, both of which protect against the development of cardiovascular disease risk factors (Carnethon et al. 2003). 
Thus, this study set out to (1) to analyze the differences in CRF and parent's overweight status between different waist-height ratio (WHtR) categories and (2) to determine the association between CRF and both maternal and parent's overweight status with $\mathrm{WHtR}$ risk group (abdominal obesity) of their offspring.

\section{Methods}

Participants and data collection -This is a cross-sectional study carried out in middle and high suburban schools comprising all the students registered in $7^{\text {th }}$ to $12^{\text {th }}$ grade during the 2006/2007 academic year. The sample used in this study comprised 779 students (472 girls and 307 boys), aged 12-18 years old along with their parents. A letter informing families that students would be measured was sent home two weeks before measurements took place and written given consent was required. This study was conducted according to the guidelines of the Helsinki Declaration of Human Studies. The Portuguese Foundation for Science and Technology provided permission to conduct this study.

\section{Anthropometric Measures}

Body height was measured to the nearest millimetre in bare or stocking feet with the adolescent standing upright against a Holtain stadiometer. Weight was measured to the nearest $0.10 \mathrm{~kg}$, lightly dressed using an electronic weight scale (Seca 708 portable digital beam scale). Body Mass Index (BMI) was calculated from the ratio of body weight $(\mathrm{kg})$ to body height $\left(\mathrm{m}^{2}\right)$.

The parents' body mass index was calculated from self-report weight and height and used to evaluate overweight status according to World Health Organisation (WHO) recommendations. First, parent's overweight status was divided into two categories: normal weight $\left(18.5 \mathrm{~kg} / \mathrm{m}^{2} \geq\right.$ BMI $<25 \mathrm{~kg} / \mathrm{m}^{2}$ ) and overweight $\left(\mathrm{BMI} \geq 25 \mathrm{~kg} / \mathrm{m}^{2}\right.$ ) (WHO 1998). Given the analysis of the associations between adolescents and parental characteristics, parents were further divided into three groups: (1) both normal-weight parents; (2) at least one overweight parent, and (3) both overweight parents.

Waist circumference measurement was taken in a standing position, to the nearest $0.1 \mathrm{~cm}$, with a tape measure midway between the lower rib margin and the anterior superior iliac spine at the end of normal expiration (Lohman et al. 1988). We then calculated waist-height ratio (WHtR) as the ratio of waist $(\mathrm{cm})$ and height $(\mathrm{cm})$, which has been used as an effective, surrogate measure of abdominal obesity and may be good predictor of cardiovascular disease risk in children (Adegboye et al. 2010). A WHtR cutoff of 0.5 has been used to define abdominal obesity for 6 to 19-year-old boys and girls (McCarthy and Ashwell 2006). Thus, for purposes of the analyses we defined two categories; the non risk group $(\mathrm{WHtR}<0.5 \mathrm{~cm})$ and at risk group (WHtR $\geq 0.5$ $\mathrm{cm})$.

\section{Cardiorespiratory Fitness (CRF)}

CRF was predicted by maximal multistage $20 \mathrm{~m}$ shuttle-run test according to procedures described in FITNESSGRAM (FITNESSGRAM 1999). FITNESSGRAM was selected because it is easy to administer to large numbers of subjects, and in addition it incorporates a choice of reliable and valid health-related physical fitness measures (FITNESSGRAM 1999). The Shuttle Run Test predicts maximal aerobic capacity and showed significant correlation with $\mathrm{VO}_{2} \mathrm{max}$ $(r=0.80)$ suggesting that it could be used as a measure of aerobic fitness in children (Vincent et al. 1999). Students were familiarized with the procedure for each test before recording data. Furthermore, the participants received verbal encouragements from the investigators in order to achieve maximum performance. The result was recorded as laps taken to complete the $20 \mathrm{~m}$ shuttle-run test. Children were then classified according to the age and sex-specific cut-off points of FITNESSGRAM criteria, as belonging to a healthy zone or under health zone.

\section{Socioeconomic status}

The highest school education achieved by either mother or father was used to define socioeconomic status (SES). Single parent families were included, and these children were classified according to school education of the single parent. SES was defined based upon the Portuguese Educational System [(1) 9 years' education or less- sub secondary level; (2) 10-12 years' education-secondary level and (3) higher education)] and then assigned into three groups ( $1=$ Low (LSES); $2=$ Middle (MSES) and $3=$ High (HSES) level of education, respectively. Similar procedures have been applied in the Portuguese context (Mota and Silva 1999). 


\section{Statistical Analysis}

Means and standard deviations were calculated to describe participants' characteristics by sex and WHtR categories. The comparisons between sex categories were done by independent $t-$ test for quantitative variables and chi-square test for qualitative variables (WHtR, CRF, parental overweight status and SES). For both genders, the independent association of predictors with $\mathrm{WHtR}$ as dependent variable (non-risk vs. risk) was examined using logistic regression analysis with parental overweight status, SES and CRF as independent variables. Statistical analysis was performed using SPSS 17 software (SPSS Inc., Chicago, IL, USA) and Microsoft Excel 2000. The level of significance was set at $p \leq 0.05$.

\section{Results}

Table I and 2 show descriptive statistics (mean and SD) of adolescents and parents by sex and WHtR categories, respectively. Boys were taller, heavier and had higher CRF values than girls $(p \leq 0.05)$, while girls had higher WHtR. Using WHtR, the prevalence of abdominal obesity was $21.3 \%$ ( $23.5 \%$ for girls and $17.9 \%$ for boys, respectively). Regardless of gender, participants within WHtR risk group had significantly $(p \leq 0.05)$ lower CRF scores than their nonrisk peers. In 45 percent $(44.6 \%)$ of the families, at least one parent was overweight, while 33 percent had two overweight parents. Only 22 percent of families were headed by two normalweight parents. Girls but not boys, belonging to WHtR risk group had significantly ( $p \leq 0.05)$ two overweight parents.

\section{Insert Table 1}

\section{Insert Table 2}

Logistic regression analysis (Figure 1) showed that boys with low CRF (OR: 6.43; Cl: 3.33 - 12.39; $p \leq 0.05$ ) were more likely to be at risk of abdominal obesity than their fit peers. Girls with low CRF (OR: 1.78; $\mathrm{Cl}: 1.14-2.78 ; p \leq 0.05)$, and having at least one overweight parent (OR: 2.50; Cl:1.07-5.85; $p \leq 0.05$ ) or having both overweight parents (OR: 4.90; Cl:2.08-11.54; $\mathrm{p} \leq 0.05$ ) were more likely to be associated with the risk of abdominal obesity.

\section{Insert Figure 1}

\section{Discussion}

This paper examined the association between CRF and abdominal obesity status in adolescents taking into account parents' overweight status and education (SES). The main finding of this study was that low CRF was a strong predictor of a higher risk of abdominal obesity in adolescence and that having two overweight parents may substantially raise the girls', but not the boys' risk of abdominal obesity.

Our data gave additional information and support with regard to the association between low CRF and abdominal obesity in both boys and girls. Our data agreed with several findings showing an inverse and significant association between CRF and adiposity in youngsters (Kim et al. 2005, Moliner-Urdiales et al. 2009). Given the fact that central obesity has been linked to metabolic and cardiovascular disease even in childhood (Rizzo et al. 2007, Teixeira et al. 2001), our data highlighted the importance of increasing CRF as a protective effect at an early age since there is some evidence that CRF levels track from childhood and adolescence into adulthood (Hasselstrom et al. 2002).

Furthermore, our data showed an interesting finding regarding the differing association between parental overweight status and their offspring's abdominal obesity expression in terms of gender. Thus, our data are worthy of analysis with regard to gender-related differences in parental-related offspring overweight influence. The present study showed those girls who had at least one overweight parent or both overweight parents were respectively, 2.9 and 4.9 times more likely to be in the at WHtR risk group than those with two normal-weight parents. In this context, our data partially agreed with other studies showing that both maternal and paternal BMI are associated with total and central adiposity in offspring (Davey Smith et al. 2007, Kivimaki et al. 2007, Labayen et al. 2010). However, on the other hand, we found that the parental-offspring overweight status influence was only statistically significant for girls.

Thus, our data raised some additional questions regarding the etiology of intergenerational obesity. Indeed to the best of our knowledge this is one of the few studies showing different 
parental influence patterns with regard to their offspring's gender. Findings from longitudinal studies have indicated that although there is evidence that patterns of lifestyle factors related to obesity often co-occur within families, these parents-descendants fatness associations may reflect a combined influence of both genetic and lifestyle factors (Labayen et al. 2010). Our study design did not allow an analysis from a genetic point of view. However, some studies have suggested that maternal BMI may be more strongly associated with offspring BMI than paternal BMI (Kivimaki et al. 2007, Lawlor et al. 2007, Whitaker et al. 2010). Other recent data have shown that both parents influence the fetal environment, and both can contribute to intergenerational increase in obesity (Abu-Amero et al. 2006). Therefore, while genetic variables are outside the scope of this paper we can assume that environmental and lifestyle factors within families may play a stronger role (Perez-Pastor et al. 2009). Previous studies have looked at the sex-specific effects between parents and their offspring, although the results have been contradictory. Some have shown youth obesity to be confined to those whose same-sex parents are obese (Perez-Pastor et al. 2009), while others have shown that maternal BMI was more strongly associated with female than with male offspring BMI but paternal associations were similar for both gender (Leary et al. 2010). Furthermore, it is also possible that influences in the postnatal life interact with the child's prenatally defined susceptibility (Cole et al. 2008). The findings of the present study agree with other data suggesting that overweight parents predicted fat gain among normal weight girls (Treuth et al. 2003). Our results may have some importance from a preventive point of view because they potentially point out some future negative health implications. Indeed, while there is evidence showing that low levels of CRF, associated with excess body fat and sedentary daily life, are significant predictors of developing heart disease (Janssen et al. 2005); the health impact of small increases in youth with lower fitness levels has also been suggested (Klasson-Heggebo et al. 2006). Despite, the tracking of obesity (Dietz 2004, Guo et al. 2002) and CRF (Janz and Mahoney 1997, Twisk et al. 2000), coupled with the decreasing trend of CRF (Martins et al. 2008) which have already been described, our findings raised concerns with regard to further social strategies at both national and community level that need to account for the family role in children and youth obesity prevention, especially in girls.

Some limitation should be recognized. The present study relied on the use of reported measures of both maternal and paternal body mass index (weight/height*height) when their offspring were recruited. Nevertheless, studies related to measured weight and height suggest that reporting, especially in young adults (Kuczmarski et al. 2001) is generally accurate, with no evidence of substantial sex related differences (Bolton-Smith et al. 2000). Furthermore, we cannot draw any conclusion regarding how much of the relationship between parental overweight and WHtR risk is due to genetic or environmental factors or to an interaction between them. Our study has as an advantage in that we used a relatively large sample and included several potential confounders.

\section{Conclusion}

Results from this study highlighted the influence of adolescents' families on abdominal obesity, especially in girls. Further, our data suggested that low CRF was a strong predictor of risk values of abdominal obesity in adolescence.

\section{References}

Abu-Amero S, Monk D, Apostolidou S, Stanier P, Moore G. 2006. Imprinted genes and their role in human fetal growth. Cytogenet Genome Res 113: 262-270.

Adegboye AR, Andersen LB, Froberg K, Sardinha LB, Heitmann BL. 2010. Linking definition of childhood and adolescent obesity to current health outcomes. Int J Pediatr Obes 5: 130-142.

Bolton-Smith C, Woodward M, Tunstall-Pedoe H, Morrison C. 2000. Accuracy of the estimated prevalence of obesity from self reported height and weight in an adult Scottish population. $J$ Epidemiol Community Health 54: 143-148.

Carnethon MR, Gidding SS, Nehgme R, Sidney S, Jacobs DR, Jr., Liu K. 2003. Cardiorespiratory fitness in young adulthood and the development of cardiovascular disease risk factors. JAMA 290: 3092-3100.

Cole TJ, Power C, Moore GE. 2008. Intergenerational obesity involves both the father and the mother. Am J Clin Nutr 87: 1535-1536; author reply 1536-1537. 
Davey Smith G, Steer C, Leary S, Ness A. 2007. Is there an intrauterine influence on obesity? Evidence from parent child associations in the Avon Longitudinal Study of Parents and Children (ALSPAC). Arch Dis Child 92: 876-880.

Deforche B, Lefevre J, De Bourdeaudhuij I, Hills AP, Duquet W, Bouckaert J. 2003. Physical fitness and physical activity in obese and nonobese Flemish youth. Obes Res 11: 434-441.

Dietz WH. 2004. Overweight in childhood and adolescence. New England Journal of Medicine 350: 855-857.

FITNESSGRAM. 1999. The Cooper Institue for Aerobic Research. FITNESSGRAM Test Administration Manual. Champaign, IL: Human Kinrtics Books.

Francis LA, Lee Y, Birch LL. 2003. Parental weight status and girls' television viewing, snacking, and body mass indexes. Obes Res 11: 143-151.

Guo SS, Wu W, Chumlea WC, Roche AF. 2002. Predicting overweight and obesity in adulthood from body mass index values in childhood and adolescence. American Journal of Clinical Nutrition 76: 653-658.

Harrap SB, Stebbing M, Hopper JL, Hoang HN, Giles GG. 2000. Familial patterns of covariation for cardiovascular risk factors in adults: The Victorian Family Heart Study. Am J Epidemiol 152: 704-715.

Hasselstrom H, Hansen SE, Froberg K, Andersen LB. 2002. Physical fitness and physical activity during adolescence as predictors of cardiovascular disease risk in young adulthood. Danish Youth and Sports Study. An eight-year follow-up study. Int J Sports Med 23 Suppl 1: S27-31.

Janssen I, Katzmarzyk PT, Boyce WF, Vereecken C, Mulvihill C, Roberts C, Currie C, Pickett W. 2005. Comparison of overweight and obesity prevalence in school-aged youth from 34 countries and their relationships with physical activity and dietary patterns. Obes Rev 6: 123132.

Janz KF, Mahoney LT. 1997. Three-year follow-up of changes in aerobic fitness during puberty: the Muscatine Study. Research Quarterly for Exercise \& Sport 68: 1-9.

Kim J, Must A, Fitzmaurice GM, Gillman MW, Chomitz V, Kramer E, McGowan R, Peterson KE. 2005. Relationship of physical fitness to prevalence and incidence of overweight among schoolchildren. Obes Res 13: 1246-1254.

Kivimaki M, Lawlor DA, Smith GD, Elovainio M, Jokela M, Keltikangas-Jarvinen L, Viikari JS, Raitakari OT. 2007. Substantial intergenerational increases in body mass index are not explained by the fetal overnutrition hypothesis: the Cardiovascular Risk in Young Finns Study. Am J Clin Nutr 86: 1509-1514.

Klasson-Heggebo L, Andersen LB, Wennlof AH, Sardinha LB, Harro M, Froberg K, Anderssen SA. 2006. Graded associations between cardiorespiratory fitness, fatness, and blood pressure in children and adolescents. British Journal of Sports Medicine 40: 25-29; discussion 25-29.

Kuczmarski MF, Kuczmarski RJ, Najjar M. 2001. Effects of age on validity of self-reported height, weight, and body mass index: findings from the Third National Health and Nutrition Examination Survey, 1988-1994. J Am Diet Assoc 101: 28-34; quiz 35-26.

Labayen I, Ruiz JR, Ortega FB, Loit HM, Harro J, Veidebaum T, Sjostrom M. 2010. Intergenerational cardiovascular disease risk factors involve both maternal and paternal BMI. Diabetes Care 33: 894-900.

Lawlor DA, Smith GD, O'Callaghan M, Alati R, Mamun AA, Williams GM, Najman JM. 2007. Epidemiologic evidence for the fetal overnutrition hypothesis: findings from the mater-university study of pregnancy and its outcomes. Am J Epidemiol 165: 418-424.

Leary S, Davey Smith G, Ness A. 2010. No evidence of large differences in mother-daughter and father-son body mass index concordance in a large UK birth cohort. Int $\mathrm{J}$ Obes (Lond).

Li L, Law C, Lo Conte R, Power C. 2009. Intergenerational influences on childhood body mass index: the effect of parental body mass index trajectories. Am J Clin Nutr 89: 551-557.

Lohman TG, Roche AF, Martorell R. 1988. Anthropometric standardization reference manual.

Martins C, Silva F, Santos MP, Ribeiro JC, Mota J. 2008. Trends of cardiovascular risk factors clustering over time: a study in two cohorts of Portuguese adolescents. Pediatric Exercise Science 20: 74-83.

McCarthy HD, Ashwell M. 2006. A study of central fatness using waist-to-height ratios in UK children and adolescents over two decades supports the simple message--'keep your waist circumference to less than half your height'. Int J Obes (Lond) 30: 988-992.

McMurray RG, Harrell JS, Deng S, Bradley CB, Cox LM, Bangdiwala SI. 2000. The influence of physical activity, socioeconomic status, and ethnicity on the weight status of adolescents. Obes Res 8: 130-139. 
Moliner-Urdiales D, Ruiz JR, Ortega FB, Rey-Lopez JP, Vicente-Rodriguez G, Espana-Romero V, Munguia-Izquierdo D, Castillo MJ, Sjostrom M, Moreno LA. 2009. Association of objectively assessed physical activity with total and central body fat in Spanish adolescents; the HELENA Study. Int J Obes (Lond) 33: 1126-1135.

Mota J, Silva G. 1999. Adolescent's physical activity with socio-economic status and parental participation among a Portuguese sample. Sport, education and Society 4: 193-199.

Mota J, Flores L, Ribeiro JC, Santos MP. 2006. Relationship of single measures of cardiorespiratory fitness and obesity in young schoolchildren. Am J Hum Biol 18: 335-341.

Ortega FB, Ruiz JR, Castillo MJ, Sjostrom M. 2008. Physical fitness in childhood and adolescence: a powerful marker of health. Int $\mathrm{J}$ Obes (Lond) 32: 1-11.

Perez-Pastor EM, Metcalf BS, Hosking J, Jeffery AN, Voss LD, Wilkin TJ. 2009. Assortative weight gain in mother-daughter and father-son pairs: an emerging source of childhood obesity. Longitudinal study of trios (EarlyBird 43). Int J Obes (Lond) 33: 727-735.

Rizzo NS, Ruiz JR, Hurtig-Wennlof A, Ortega FB, Sjostrom M. 2007. Relationship of physical activity, fitness, and fatness with clustered metabolic risk in children and adolescents: the European youth heart study. J Pediatr 150: 388-394.

Sardinha LB, Teixeira PJ, Guedes DP, Going SB, Lohman TG. 2000. Subcutaneous central fat is associated with cardiovascular risk factors in men independently of total fatness and fitness. Metabolism 49: 1379-1385.

Sardinha LB, Santos R, Vale S, Silva AM, Coelho e Silva MJ, Raimundo A, Moreira H, Baptista F, Mota J. 2010. Prevalence of overweight and obesity among Portuguese Youth: a study in a representative sample of 10-18 years old children and adolescents. In press International Journal of Pediatric Obesity.

Teixeira PJ, Sardinha LB, Going SB, Lohman TG. 2001. Total and regional fat and serum cardiovascular disease risk factors in lean and obese children and adolescents. Obes Res 9: 432-442.

Treuth MS, Butte NF, Sorkin JD. 2003. Predictors of body fat gain in nonobese girls with a familial predisposition to obesity. American Journal of Clinical Nutrition 78: 1212-1218.

Twisk JW, Kemper HC, van Mechelen W. 2000. Tracking of activity and fitness and the relationship with cardiovascular disease risk factors. Med Sci Sports Exerc 32: 1455-1461.

Vincent SD, Barker R, Clarke M, Harrison J. 1999. A comparison of peak heart rates elicited by the 1-mile run/walk and the progressive aerobic cardiovascular endurance run. Research Quarterly for Exercise \& Sport 70: 75-78.

Whitaker KL, Jarvis MJ, Beeken RJ, Boniface D, Wardle J. 2010. Comparing maternal and paternal intergenerational transmission of obesity risk in a large population-based sample. Am J Clin Nutr 91: 1560-1567.

WHO. 1998. Obesity: preventing and managing the global epidemic. 1-278.

WHO. 2000. Obesity: Preventing and managing the global epidemic.

Wijga AH, Scholtens S, Bemelmans WJ, de Jongste JC, Kerkhof M, Schipper M, Sanders EA, Gerritsen J, Brunekreef B, Smit HA. 2010. Comorbidities of obesity in school children: a crosssectional study in the PIAMA birth cohort. BMC Public Health 10: 184. 
Table 1 - Sample Characteristics

\begin{tabular}{|c|c|c|c|c|c|}
\hline \multicolumn{2}{|c|}{ Characteristics } & $\begin{array}{l}\begin{array}{l}\text { Total } \\
(\mathrm{n}=779)\end{array} \\
\end{array}$ & $\begin{array}{l}\text { Girls } \\
(n=472)\end{array}$ & $\begin{array}{l}\text { Boys } \\
(n=307)\end{array}$ & $p$ \\
\hline \multicolumn{2}{|l|}{ Age (years) } & $15.07 \pm 1.86$ & $15,22 \pm 1.74$ & $14.84 \pm 2.01$ & 0.006 \\
\hline \multicolumn{2}{|l|}{ Weight (kg) } & $59.64 \pm 11.76$ & $57.95 \pm 9.87$ & $62.23 \pm 13.80$ & 0.000 \\
\hline \multicolumn{2}{|l|}{ Height $\left(m^{2}\right)$} & $1.65 \pm 0,09$ & $1.61 \pm 0.07$ & $1.68 \pm 0.10$ & 0.000 \\
\hline \multicolumn{2}{|c|}{ Body Mass Index (BMI) $\left(\mathrm{kg} / \mathrm{m}^{2}\right)$} & $21.93 \pm 3.47$ & $22.10 \pm 3.35$ & $21.68 \pm 3.64$ & 0.099 \\
\hline \multicolumn{2}{|c|}{ Waist/height Ratio (WHtR) (cm) } & $0.46 \pm 0.05$ & $0.47 \pm 0.05$ & $0.46 \pm 0.06$ & 0.017 \\
\hline \multicolumn{2}{|c|}{ Cardiorepiratory Fitness (CRF) (laps) } & $41.31 \pm 20.20$ & $31.37 \pm 12.09$ & $56.59 \pm 20.63$ & 0.000 \\
\hline \multicolumn{2}{|c|}{ Father BMI $\left(\mathrm{kg} / \mathrm{m}^{2}\right)$} & $26.64 \pm 3.34$ & $26.60 \pm 3.32$ & $26.71 \pm 3.38$ & 0.666 \\
\hline \multicolumn{2}{|c|}{ Mother BMI $\left(\mathrm{kg} / \mathrm{m}^{2}\right)$} & $25.58 \pm 3.94$ & $25.78 \pm 3.99$ & $25.26 \pm 3.84$ & 0.072 \\
\hline \multirow{2}{*}{ WHtR (\%) } & $<0.5$ & 78.7 & 76.5 & 82.1 & \multirow{2}{*}{0.062} \\
\hline & $>0.5$ & 21.3 & 23.5 & 17.9 & \\
\hline \multirow{2}{*}{ CRF (\%) } & Under Health Zone & 44.3 & 49.8 & 35.8 & \multirow{2}{*}{0.000} \\
\hline & Health Zone and Above & 55.7 & 50.2 & 64.2 & \\
\hline \multirow{3}{*}{ POS (\%) } & Both normal weight parents & 18.2 & 15.7 & 22.1 & \multirow{3}{*}{0.051} \\
\hline & At least one overweight parent & 48.7 & 51.3 & 44.6 & \\
\hline & Both overweight parents & 33.1 & 33.1 & 33.2 & \\
\hline \multirow{3}{*}{ SES (\%) } & Low SES & 56.9 & 58.7 & 54.1 & \multirow{3}{*}{0.374} \\
\hline & Middle SES & 23.7 & 23.3 & 24.4 & \\
\hline & High SES & 19.4 & 18 & 21.5 & \\
\hline
\end{tabular}

WHtR - Waist/height Ratio ; CRF - cardiorespiratory fitness; POS - parental overweight status; SES - socioeconomic status; ns - $p>0.05$ 
Table 2 - Mean and SD of adolescents and parents characteristics by WHtR category within each sex

\begin{tabular}{|c|c|c|c|c|c|c|c|}
\hline & & Girls & & & Boys & & \\
\hline \multicolumn{2}{|c|}{ Characteristics } & $\begin{array}{l}\text { WHtR }<0.5 \\
(n=361)\end{array}$ & $\begin{array}{c}\text { WHtR }>0.5 \\
(n=111)\end{array}$ & $p$ & $\begin{array}{l}\text { WHtR }<0.5 \\
(n=252)\end{array}$ & $\begin{array}{l}\text { WHtR }>0.5 \\
(n=55)\end{array}$ & $p$ \\
\hline \multicolumn{2}{|l|}{ Age (years) } & $15.23 \pm 1.72$ & $15.21 \pm 1.82$ & 0.904 & $15.00 \pm 1.91$ & $14.07 \pm 2.31$ & 0.007 \\
\hline \multicolumn{2}{|l|}{ Weight (kg) } & $55.26 \pm 8.16$ & $66.70 \pm 9.93$ & 0.000 & $59.89 \pm 10.48$ & $72.95 \pm 20.66$ & 0.000 \\
\hline \multicolumn{2}{|l|}{$\mathrm{BMI}\left(\mathrm{kg} / \mathrm{m}^{2}\right)$} & $20.92 \pm 2.37$ & $25.95 \pm 3.21$ & 0.000 & $20.69 \pm 2.34$ & $26.19 \pm 4.90$ & 0.000 \\
\hline \multicolumn{2}{|c|}{ Waist/height Ratio (WHtR) (cm) } & $0.44 \pm 0.03$ & $0.54 \pm 0.04$ & 0.000 & $0.44 \pm 0.03$ & $0.55 \pm 0.06$ & 0.000 \\
\hline \multicolumn{2}{|c|}{ Cardiorepiratory Fitness (CRF) (laps) } & $32.61 \pm 12.50$ & $27.34 \pm 9.64$ & 0.000 & $60.83 \pm 19.26$ & $37.15 \pm 14.81$ & 0.000 \\
\hline \multicolumn{2}{|c|}{ Father BMI $\left(\mathrm{kg} / \mathrm{m}^{2}\right)$} & $26.37 \pm 3.16$ & $27.35 \pm 3.70$ & 0.006 & $26.36 \pm 3.24$ & $28.30 \pm 3.59$ & 0.000 \\
\hline \multicolumn{2}{|c|}{ Mother BMI $\left(\mathrm{kg} / \mathrm{m}^{2}\right)$} & $25.24 \pm 3.60$ & $27.59 \pm 4.64$ & 0.000 & $25.06 \pm 3.70$ & $26.20 \pm 4.37$ & 0.046 \\
\hline CRF (\%) & $\begin{array}{l}\text { Under Health Zone } \\
\text { Health Zone and Above }\end{array}$ & $\begin{array}{l}46.3 \\
53.7\end{array}$ & $\begin{array}{l}61.3 \\
38.7\end{array}$ & 0.006 & $\begin{array}{l}28.2 \\
71.8\end{array}$ & $\begin{array}{l}70.9 \\
29.1\end{array}$ & 0.000 \\
\hline \multirow{3}{*}{ POS (\%) } & Both normal weight parents & 18.6 & 6.3 & & 23.8 & 14.5 & \multirow{3}{*}{0.261} \\
\hline & At least one overweight parent & 53.2 & 45 & 0.000 & 44.4 & 45.5 & \\
\hline & Both overweight parents & 28.3 & 48.6 & & 31.7 & 40 & \\
\hline \multirow{3}{*}{ SES (\%) } & Low SES & 57.6 & 62.2 & & 54 & 54.5 & \multirow{3}{*}{0.753} \\
\hline & Middle SES & 23 & 24.3 & 0.369 & 23.8 & 27.3 & \\
\hline & High SES & 19.4 & 13.5 & & 22.2 & 18.2 & \\
\hline
\end{tabular}


Figure 1 - Logistic Regression Analysis
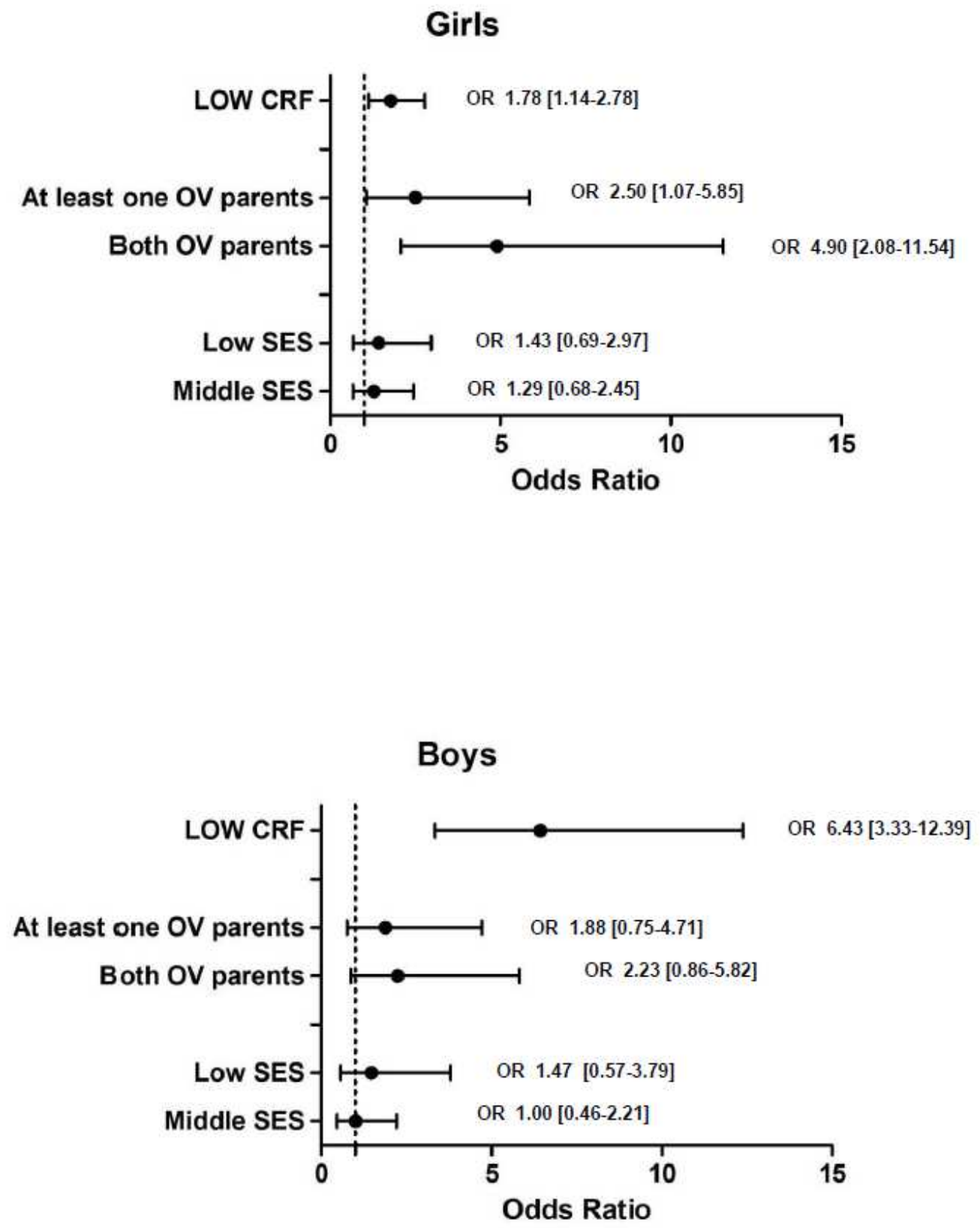